\section{NOVA TELLVS}

\section{kyth}

Nova Tellus

ISSN: 0185-3058

novatelu@servidor.unam.mx

Centro de Estudios Clásicos

México

Ramírez Vidal, Gerardo

Fray Diego Valadés y el tratado seudoluliano In rhetoricam isagoge

Nova Tellus, vol. 30, núm. 1, 2012, pp. 167-197

Centro de Estudios Clásicos

Distrito Federal, México

Disponible en: http://www.redalyc.org/articulo.oa?id=59128312007

- Cómo citar el artículo

- Número completo

- Más información del artículo

- Página de la revista en redalyc.org

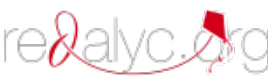

Sistema de Información Científica

Red de Revistas Científicas de América Latina, el Caribe, España y Portugal

Proyecto académico sin fines de lucro, desarrollado bajo la iniciativa de acceso abierto 


\title{
Fray Diego Valadés \\ y el tratado seudoluliano In rhetoricam isagoge
}

\author{
Gerardo RAMÍREZ VIDAL \\ Universidad Nacional Autónoma de México \\ grvidal18@gmail.com
}

\begin{abstract}
Resumen: Para la elaboración de las páginas 56-74 de su Rhetorica christiana (1579), fray Diego Valadés copió la primera parte del tratado seudoluliano In rhetoricam isagoge, que trata sobre los subiecta y praedicata, los cuales constituyen la materia de la retórica. No se trata, sin embargo, de una copia fiel, pues el franciscano modifica el texto con alguna frecuencia mediante la supresión, adición, sustitución o transposición de palabras o pasajes a lo largo de esta sección. Aun cuando se trata de una copia de un texto seudoluliano, no podemos afirmar que fray Diego Valadés haya sido un seguidor de Raimundo Lulio en la Nueva España, pues elaboró las páginas indicadas durante su estancia en Roma, donde tuvo acceso a la mayoría de sus fuentes, cuando fungía como Procurador General de la orden franciscana, esto es, en la última parte de su vida transcurrida en Italia. Además, utilizó su material bibliográfico de una forma tal que hace dudar incluso de que él hubiera sido seguidor del teólogo y misionero catalán.
\end{abstract}

\section{Diego Valadés and the Pseudo-Lullian Work In rhetoricam isagoge}

ABSTRACT: When drafting pages 56 to 74 of his Rhetorica christiana (1579), Diego Valadés copied out the first part of the pseudo-Llullian work In rhetoricam isagoge, dealing with the subiecta and praedicata, which are the subject matter of rhetoric. However, it is not a faithful copy, in so far as the Franciscan quite often modifies the text by deleting, adding, replacing or transposing words or passages in this section. Even though Diego Valadés copied out of a pseudo-Llullian text, we may not simply say that he was a follower of Ramon Llull in New Spain, as he wrote the pages in issue during his stay in Rome, where he had access to most of his sources in his capacity as Procurador General of the Franciscan order, ie, during the latter part of his life in Italy. Furthermore, he used those sources so as to cast doubt on his supposed attachment to the Catalan theologian and missionary.

Palabras ClaVe: Fray Diego Valadés, Raimundo Lulio, retórica, Nueva España.

KeYwords: Diego Valadés, Ramon Llull, rhetoric, New Spain.

FECHA DE RECEPCIÓN: 10 de febrero de 2012.

FECHA DE ACEPTACIÓN: 24 de marzo de 2012. 



\title{
Fray Diego Valadés y el tratado seudoluliano In rhetoricam isagoge ${ }^{1}$
}

\author{
Gerardo RAMÍREZ VIDAL
}

Los estudios actuales de los autores y de las fuentes novohispanas se encuentran sometidos con frecuencia a una serie de obstáculos que nos llevan a deformar de manera involuntaria nuestro pasado. No sólo la pérdida de numerosos documentos, la falta de apoyo institucional o el escaso desarrollo de los métodos de estudio, sino también la tradición, las orientaciones ideológico-religiosas y nuestros prejuicios nos orillan a ponderar de manera parcial o equivocada nuestro pasado. Entre los personajes consagrados por los especialistas destaca el fraile franciscano Diego Valadés (1533-c. 1584), de cuya obra de 1579, Rhetorica christiana, publicada en Perusa, Italia, se han escrito alabanzas exageradas al punto de considerar al autor como mestizo, protector de los indios, eminente latinista, entre otras cosas, asunto del que aquí no voy a ocuparme.

Los errores de interpretación se deben en gran medida a que no se ha tenido cuidado de la fijación del texto y, en particular, de la intertextualidad o presencia del hipotexto en el hipertexto: cita, plagio o copia y alusión. Consideramos que el segundo de la tríada anterior es el cimiento que sostiene toda la obra. En efecto, podemos observar que, en la elaboración de su tratado, fray Diego Valadés copió pasajes extensos de obras ya publicadas, a las que pudo haber tenido acceso en la Biblioteca Vaticana. ${ }^{2}$

${ }^{1}$ Una versión breve de este trabajo fue presentada en el XXIV Encuentro Nacional de Investigadores del Pensamiento Novohispano, celebrado en la ciudad de Guadalajara, Jalisco, del 3 al 5 de noviembre de 2011. Aprovecho para agradecer a Marco Mancera Alba la lectura cuidadosa del original.

${ }^{2}$ Valadés pudo haber habitado en el convento franciscano de San Pietro en Montorio, al sur del Vaticano, de manera que podía trasladarse a ese lugar donde residía el Papa y donde se encontraba ya la famosa Biblioteca Vaticana, fundada en 1448. 
Como hemos expuesto en otro estudio (Ramírez Vidal, 2012), la parte relativa a la memoria, considerada por muchos estudiosos como una de las aportaciones más originales de esa obra, es una reproducción del Congestorium memoriae de Johannes von Romberch, publicado en Venecia en 1520. Por ello, todos los elogios y reflexiones que se han hecho sobre la nemotecnia valadesiana son inaplicables al propio fraile. Podríamos pensar que, por lo menos, tenemos a la mano en el hipertexto (Valadés) una reproducción útil de las partes más importantes del hipotexto (von Romberch), pero en realidad los capítulos dedicados a la memoria no tienen valor alguno, porque nuestro fraile alteró sensiblemente el orden del texto original mediante transposiciones, además de realizar sustituciones, mutilaciones y agregados que afectan de manera grave el texto resultante. ${ }^{3}$

Puede observarse que Valadés procede de la misma manera a lo largo de la Rhetorica christiana, y es muy probable que todo el tratado, salvo secciones menores, sea una copia mal elaborada por nuestro franciscano de obras que circulaban cuando él residía en Italia. De tal manera, muchas de las hipótesis expuestas hasta hoy en torno a esa obra deberán ser objeto de revisión. Por ejemplo, se había pensado que algunos discursos con que Valadés ilustra los diferentes géneros retóricos son parodias de los huehuetlahtolli, discursos de origen indígena, pero se ha descubierto que en realidad son traducciones de textos europeos. ${ }^{4} \mathrm{Al}$ revisar otros pasajes de la Rhetorica christiana, se pueden encontrar las mismas prácticas intertextuales.

En las páginas que siguen se estudian los capítulos del VI al XVIII (pp. 56-74) del libro segundo, los cuales tratan sobre los subiecta y los praedicata de la retórica. Esos 13 capítulos son muy importantes, entre otras razones, porque probarían la supuesta influencia del lulismo en fray Diego Valadés, influencia que también se encontraría en otros autores, como el propio fray Bartolomé de las Casas. ${ }^{5}$

${ }^{3}$ Excepto tal vez la parte relativa al Tabernáculo de Dios, en el capítulo XXIX. Algunas reflexiones sobre la nemotecnia en la evangelización de los indígenas de México pueden tener algún interés.

${ }^{4}$ Cf. Chaparro Gómez, 2004, pp. 258-259, etc. Otro caso es la copia que Valadés hizo de pasajes de la obra de Agustín Valerio, Rhetorica ecclesiastica, publicada en 1575. Por ejemplo, en el primer capítulo (p. 3) se encuentran pasajes copiados de la página 120 de la obra de Valerio (cf. Chaparro Gómez, 2008), o en la página 55, de la página 4, etcétera.

${ }^{5}$ Aunque la influencia del pensamiento de Raimundo Lulio en la Rhetorica christiana no se limita a los subiecta y a los praedicata de la retórica desarrollados en los capítulos 
El propósito de este ensayo es doble. Por una parte se busca mostrar que, para elaborar esa amplia sección, Valadés se limitó a copiar largos pasajes de una obrita seudoluliana intitulada In rhetoricam isagoge, atribuida a un tal Remigio Rufo Cándido de Aquitania ${ }^{6}$ y publicada en 1515 en la imprenta de Josse Bade. ${ }^{7}$ El franciscano amplió su versión con pasajes extraídos de otras obras importantes que tenía a su disposición en el Vaticano, haciendo correcciones y agregados en general poco afortunados. Lo anterior queda muy claro gracias al análisis ecdótico de las relaciones intertextuales de esos trece capítulos del tratado franciscano (hipertexto) con los pasajes copiados de otras obras (hipotextos), en particular la de Remigio Rufo. ${ }^{8}$

Por otra parte, con base en el análisis intertextual, intentamos refutar también la hipótesis de que los pasajes indicados prueban la supuesta influencia de Raimundo Lulio en Diego Valadés, o por lo menos instamos a tener mayor cuidado al atribuir al franciscano una influencia lulista a partir de las semejanzas entre ambos. En efecto, las fuentes de las que el novohispano obtiene su material no se encontraban en los fondos bibliotecarios a los que él tuvo acceso en la Nueva España. Por esta razón, es obvio que pudo haberlas consultado sólo durante su estancia en Italia. En consecuencia, si los datos anteriores son correctos, Valadés pudo haberse hecho lulista sólo al final de su vida. Sin embargo, el simple copiado de una obra no es prueba de influencia alguna, e incluso las semejanzas entre dos obras (en nuestro caso entre Lulio y Diego) no

en cuestión, los estudiosos han llamado la atención fundamentalmente sobre esos aspectos. También las imágenes podrían mostrar esa influencia, pero su análisis requeriría de otro espacio.

${ }^{6}$ El autor se llama Remigio Rufo, pero nada se sabe de él, por lo que "se piensa que más bien se trata de un apodo utilizado por el mismo Bernardo de Lavinheta” (Báez Rubí, 2005, p. 141, n. 95).

${ }^{7}$ Cf. M. Beuchot, 1997 y 1998. La edición original era Raemundi Lulli, in Rhetoricen Isagoge perspicacibus ingeniis expectata, [Paris] 1515. Beuchot registra la siguiente ficha: Remigio Rufo Cándido de Aquitania, Isagoge in rhetoricam M. Raimundi Lulii arti ipsius accomodata, Paris, 1915. Para este artículo se ha revisado la versión original, pero, por comodidad, se cita a partir de la edición de 1617, pp. 178-223 (cf. Bibliografía). Sobre el impresor Bade, cf. Báez Rubi, 2005, pp.139-142.

${ }^{8}$ No presentamos una relación completa de los 13 capítulos, pues ello requeriría de un espacio mucho más amplio del que disponemos. Sin embargo, la exposición global y los ejemplos aportados son suficientes para demostrar lo que pretendemos. 
deben explicarse necesariamente como una relación de causa-efecto o de antecedente-consecuente.

$$
* * *
$$

Debe observarse en principio que la relación intertextual entre Valadés y Rufo no es desconocida. Ya en 1992 Mauricio Beuchot observó semejanzas entre ambas obras, y llegó a la conclusión de que el franciscano habría recibido la influencia del teólogo español, del cual sería tal vez el único seguidor en la Nueva España. ${ }^{9}$

Recientemente, Domínguez Reboiras (2010) ha considerado que la obra de fray Diego Valadés es "una muestra palpable de la importancia del lulismo en la entraña de este proceso, calificado como utópico", y luego afirma que "la Rhetorica de Valadés se basa fundamentalmente en una obra seudoluliana: In rhetoricam isagoge (Paris 1515)". Asimismo, aclara que:

los elementos específicamente lulistas que aparecen en la obra valadesiana son las nueve dignidades divinas o predicados, los nueve sujetos de la scala creaturarum a través de la cual, el predicador asciende y desciende por los grados de las causas. Una jerarquización del universo tomada de seudo-Dionisio el Areopagita se mezcla con la representación del arbor apostolicalis y arbor imperialis lulianos. La particularidad de Valadés radica en que intenta adaptar los elementos lulianos al contexto novohispano (Domínguez Reboiras, 2010, p. 384).

De tal modo, gracias al cotejo de ambas obras, Valadés se presenta como el ejemplo más claro de la influencia lulista en la Nueva España.

Ya hace algunos años, en 2005, Linda Báez Rubí observó las grandes semejanzas entre ambas obras, la franciscana y la seudoluliana, y elaboró un amplio y cuidadoso análisis del opúsculo en las páginas 138-140 de su Mnemosyne novohispana, e incluso hizo un cotejo puntual de algunos pasajes en los que se muestra que Valadés copió al seguidor de Lulio. La autora llega a decir:

Al comparar la estructura del In rhetoricam isagoge con la de la Rhetorica christiana de Valadés, no sólo encontramos demasiadas similitudes, sino que el texto es el mismo que en el pasaje referente a la materia de predicación [...]

${ }^{9}$ Cf. M. Beuchot, 1992 y 2010, cuyo capítulo segundo lleva por título "Retórica y lulismo en Diego Valadés”. Cf. también Chaparro Gómez, 2002, p. 640, n. 22. 
Podemos afirmar que toda la materia del ars dicendi, tanto en el Isagoge como en la Rhetorica, es igual (Báez Rubí, 2005, p. 152).

Para mostrar lo anterior coteja un pasaje de la página 179 del tratado seudoluliano con el correspondiente de la página 56 del texto novohispano, aunque en traducción al español y no en latín.

A pesar de su importante constatación, la autora no considera que se trate de una copia, sino que presenta las correspondencias como si se debieran a procedimientos diferentes en ambos autores. Así, hace las siguientes afirmaciones: "Valadés lleva a cabo el mismo tratamiento sobre los sujetos que la Isagoge" (p. 152); "El mismo procedimiento y la temática empleados por el texto seudoluliano para explicar los predicados es el que expone Valadés en su Rhetorica" (p. 255); "Vemos que, en la Rhetorica y el Isagoge, las nueve dignidades se dividen en tres grupos" (p. 155); "una vez más, Valadés hizo suya la misma concepción, de tal manera que la persona del hijo se consideró así..."; el tratado seudoluliano "comparó el principians lulista con la trinidad cabalística del ser esencia y, lo más importante, es que Valadés simplemente adoptó la misma idea". A veces incluso llega a considerar que el tratado de Remigio Rufo es una fuente de Valadés, como cuando afirma: "Ni en la Rhetorica [de Valadés] ni en su fuente, In rhetoricam isagoge, se nos ofrece una explicación de esta división triádica sobre las dignidades". Aún más, al final trata de rechazar que se trate de una "simple copia". Afirma: "No cabe duda de que Valadés basó su Rhetorica en este tratado seudoluliano; sin embargo, sí hay diferencias en ambas obras". No me parece que Báez Rubí haya presentado ninguna prueba de esa diferencia. Observa que el método lulista se produce en contextos diferentes, y a partir de ello concluye: "Creo que esto salva a Valadés de no haber realizado una simple copia mecánica del texto seudolulista".

Sería mejor admitir que nuestro autor no se limitó a elaborar una reproducción mecánica sólo de ese tratado, sino que su copia se extendió a otras obras, y que esta forma de trabajo tampoco se restringió a los pasajes ahí confrontados, sino que procedió del mismo modo a lo largo de las casi veinte páginas de los capítulos que tratan sobre el tema de los subiecta. De las tres formas intertextuales (cita, plagio y alusión), ${ }^{10}$

\footnotetext{
${ }^{10}$ Aquí seguimos la clasificación de Genette, 1989, p. 10, quien define el plagio como "una copia no declarada pero literal”, aunque las relaciones textuales son más amplias y complejas.
} 
el texto valadesiano que analizaremos constituye una copia, aunque, desde las convenciones actuales, debería considerarse un plagio, pues se trata de un texto que el lector considera auténtico del autor, quien no indica sus fuentes. ${ }^{11}$ Se trata de una especie de centón no señalado: un hipertexto producido a partir de varios hipotextos. En efecto, podemos observar que Valadés, sin indicarlo, toma como base la obra anónima, introduciendo modificaciones y agregados que dan como resultado una composición sensiblemente diferente del original, pues lo que agrega es más extenso que el texto del propio tratado seudoluliano. Para mostrar lo anterior examinaremos en primera instancia los cambios o alteraciones de ese tratado, que podemos dividir en cuatro tipos: adición, supresión, sustitución y transposición.

Antes de proceder, observemos el contenido de la obra de Remigio Rufo. Se trata de una introducción a la retórica de carácter no tradicional, pues no se basa en la división de la retórica en sus partes canónicas, aunque Remigio Rufo la conocía. Divide la retórica en dos partes: en la primera (1617,pp. 179-215) ${ }^{12}$ hace una presentación de los subiecta y de los praedicata, que se refieren propiamente a la materia retórica, en particular a la retórica cristiana; en seguida elabora una larga serie de esquemas que sintetizan casi en su totalidad el Panepistemon de Angel Poliziano, publicado en 1472, asunto que aquí no vamos a tratar (cf. Pereira, 1974). En la segunda parte, de tan solo siete páginas (1617, pp. 216-223), el autor da cuenta de las applicationes.

En seguida notemos diferentes tipos de modificaciones que opera Valadés sobre la obra seudoluliana, a partir de la primera página de ésta (1617, p. 179), que corresponde a la primera sección de la primera parte, referida a los subiecta. Nos daremos cuenta de que desde la primera página nuestro autor $(1579$, p. 56) trabaja de una manera inapropiada.

En primer lugar, Valadés acostumbra romper la dispositio original. En este caso, su copia del In rhetoricam isagoge no comienza al inicio de capítulo (en este caso el VII), sino 18 líneas antes de su inicio, de manera que destruye la secuencia original. Asimismo, habrá que observar, en el plano

${ }^{11}$ Se trata de un plagio sui generis, pues no podemos presumir dolo por parte del autor, ni violación de la propiedad intelectual, convención que no existía en la época de Valadés, como veremos después.

12 Recuérdese que citamos de la edición de 1617, y no de la primera edición de 1515 (cf. supra n. 7). 
del contenido, que con frecuencia corta partes sustantivas de un secuencia de un bloque o argumento. En su copia de Remigio Rufo suprime las primeras 10 líneas del original. Aunque en este caso esta supresión es apropiada, con frecuencia incurre en graves omisiones, como veremos adelante.

En tercer lugar, Valadés junta fragmentos sin diferenciar las fuentes. En la composición que estamos analizando une un texto a otro sin empezar en párrafo aparte, ni siquiera con punto y seguido, sino que se contenta con enlazar ambos pasajes mediante la conjunción et sic. Podemos constatar que el capítulo VI de la Rhetorica de Valadés, relativo al sujeto y materia de la retórica (De subiecto, et materia Rhetorices), mezcla fragmentos de diferente origen. Inmediatamente antes de las 18 líneas mencionadas se encuentran seis que provienen del libro I, capítulo 3 del De arte rhetorica ${ }^{13}$ de Cypriano Soárez. Este jesuita español termina su capítulo 3 de la siguiente manera:

Sed hoc interest inter alias artes, excepta Dialectica, et eloquentia, quod caeterae fere artes se ipsae per se tuentur singulae, bene dicere autem, quod est scienter, et perite et ornate dicere, non habet definitam aliquam regionem, cuius terminis septa teneatur. Omnia quaecumque in hominum disceptationem cadere possunt, bene sunt ei dicenda, qui hoc se posse profitetur, aut eloquentiae nomen relinquendum est.

Pero entre las artes, exceptuando la dialéctica y la elocuencia [es decir, la retórica], existe lo siguiente, que más o menos todas las artes se consideran a sí mismas autónomas, pero el hablar bien, que consiste en hablar con conocimiento de causa, con eficacia y con elegancia, no tiene un campo definido, dentro de cuyos límites se encuentre circunscrita. Y cualquier cosa que pueda caer en el debate entre los hombres debe ser bien dicha por aquel que pretende poseer esta capacidad, pero de no ser así, debe abandonar el nombre de elocuencia.

Valadés toma este pasaje, e inmediatamente después empieza a reproducir el texto del In rhetoricam isagoge, quedando de la siguiente manera: ... aut eloquentiae nomen relinquendum est, et sic tota dicendi ars dividitur in subiecta et applicatione $\left(1617\right.$, p. 180). ${ }^{14}$

En cuarto lugar, el franciscano une pasajes cuya relación con frecuencia no es clara entre sí, o que incluso a veces tratan asuntos diferentes.

${ }^{13}$ Esta obra fue publicada en Coimbra en 1562; entre otras muchas ediciones se encuentra la de Venecia de 1568.

${ }^{14}$ Nos hemos permitido adecuar la puntuación del original, la "u" semivocálica y el signo "\&", así como otras abreviaturas tipográficas comunes en la época de Valadés. 
Como podrá observarse, los fragmentos que han sido unidos, en efecto, no tienen una clara correspondencia entre sí. Cypriano trata sobre la universalidad del campo de la retórica y recurre a un pasaje del De oratore de Cicerón (II 3.5: caeterae... relinquendum est), quien, a su vez, se refería a que el buen orador debe necesariamente tener amplios conocimientos. Sin embargo, Valadés, luego de copiar el pasaje de Soárez, agrega de manera abrupta, mediante el nexo et sic..., la división de la retórica en dos partes (los subiecta y las applicationes). El franciscano teje de modo inapropiado los pasajes de sus dos fuentes.

En la primera página de los sujetos y predicados hemos visto cómo Valadés recurre a una serie de expedientes en la elaboración de sus capítulos sobre los sujetos y predicados de la retórica cristiana. Se trata de una copia o plagio de varias fuentes que mezcla recurriendo a la adición y supresión, además de romper con la secuencia discursiva. Veremos estos y otros recursos en las páginas siguientes.

Luego de transcribir las líneas indicadas de Soárez y de Remigio Rufo, nuestro autor prosigue copiando del tratado seudoluliano, con algunos cambios, las partes siguientes a in subiecta et applicatione de la siguiente manera:

Subiecta quae plerique locos, seu terminos <sive res> apellant in universum sunt novem, Deus, Angelus, coelum, homo, imaginatio, sensus, vis vegetandi, elementativa, et instrumentativa. Dicuntur subiecta vel materia, quia de iis principaliter loquimur: aut quia ab iis sumuntur confirmationes, et confutationes. Ne tamen modo, longo studiosos teneam sermone, sumuntur ab omnibus his subiectis confirmationes.

Los sujetos, que muchos llaman lugares, o términos $<0$ asuntos $>$, son en general nueve: Dios, ángel, cielo, hombre, imaginación, sentido, fuerza vegetativa, elementativa e instrumentativa. Se llaman sujetos o materia, porque hablamos principalmente acerca de ellos, o porque de estos se obtienen las confirmaciones y las confutaciones. Sin embargo, para no detener a los estudiosos con un amplia explicación, de todos estos sujetos se toman las confirmaciones.

Algunos cambios son superficiales, pero otros alteran el contenido y el sentido del texto. Primero notamos la supresión de sive res, que hemos puesto entre paréntesis angulares, después de terminos. Esta modificación altera el sentido del pasaje, porque en el original se entiende que los subiecta y terminos son los asuntos, el contenido, frente a los verba, que es el estilo, la expresión. Además, emplea in universum en 
vez del in toto de Remigio Rufo, aunque este cambio no parece importante. En seguida encontramos otro cambio que sí altera el sentido, pues el texto resultante relativo a los subiecta es imaginatio, sensus y vis vegetandi, mientras que en la fuente o hipotexto se lee: imaginativa, sensitiva y vegetativa. Esta modificación es más grave, porque cambia la nomenclatura de esos elementos, que no se emplean para designar subiecta. En efecto, la imaginatio no es subiectum, sino una función del cerebro, y lo mismo sucede con sensus. En cuanto a la vis vegetandi, se refiere a una de las potencias, llamada también anima vegetativa.

Deberá observarse, además, que Remigio Rufo presenta el orden canónico lulista de menor a mayor importancia, comenzando por el primer $\mathrm{su}$ biectum, que es el instrumentativum, y terminado por el noveno y último, que es Deus. ${ }^{15}$ En cambio, Valadés presenta al orden inverso. Lo anterior parece una transformación radical, de modo que más que ascenso parecería descenso. La expresión Ne tamen modo, longo studiosos teneam sermone es un agregado del franciscano para transformar en un texto corrido el cuadro que aparece en seguida en el tratado de Remigio Rufo, pero se trata de un enunciado repetitivo y, por tanto, innecesario, independientemente de que se refiera sólo a las confirmaciones y olvide las refutaciones.

En seguida, Valadés muestra las tres fuentes de las que se pueden elaborar las confirmationes: auctentice, similiter, et exempli causa. Sin embargo, en el tratado seudoluliano las partes se enuncian de la siguiente manera: authentice, similitudinarie, exemplariter, es decir, mediante "formas genuinas" (o directas), mediante "indirectas" o bien mediante "ejemplos". Luego Valadés introduce un pasaje donde explica en qué consiste cada una de estas fuentes, pero se trata de un agregado, una explicación, tal vez debida al propio franciscano, quien parece no comprender el sentido de los términos. Remigio Rufo explica esos conceptos en la página 221 (siempre de la edición de 1617). Hay diferentes formas de obtener los argumentos. La primera es de las palabras directas de Dios, de los ángeles y de los hombres (en este último caso, también de las leyes y de los gobernantes); la segunda, llamada también per similitudo,

15 Los nueve sujetos forman parte de la scala creaturarum que se encuentra en el Ars inventiva de Raimundo Lulio, publicada en 1290 (Montpellier). Cf. sin embargo, De conversione subiecti et praedicati et medii (p. 163): Iste liber dividitur in decem distinctiones. Quae sunt haec Ordinatio, Deus, angelus, caelum, homo, imaginatio, sensus, vegetatiua, elementativa et instrumentiva. 
mediante comparaciones, y en este caso se pueden obtener de todos los nueve subiecta, refiriéndose a cada uno de éstos, y finalmente mediante ejemplos (per exempla), de la hormiga, el león o la tierra, sobre todo de los tres primeros sujetos: Dios, ángeles y hombres. Las historias sagradas proporcionan un numeroso material de esta naturaleza (exemplorum copia). Serían, pues, tres tipos de fuentes de la argumentación.

El texto de Valadés es muy inferior al de Rufo. Para él, la función de la comparación y del ejemplo es hacer más atentos a los oyentes (ut attentiores reddat auditores) y excitar sus mentes a investigar los misterios. Se trata de una interpretación muy equivocada del propio Valadés (o, eventualmente, de su fuente). Además, habrá que observar que la expresión exempli causa tiene una función diferente de exemplariter, pues esta última es de carácter argumentativo. Las explicaciones del novohispano dejarían completamente confundido al lector o al traductor.

Por lo tanto, hemos visto que Valadés utiliza las cuatro operaciones en su reproducción textual del comienzo del tratado seudolulista. No se trata de procedimientos aislados, sino recurrentes. En efecto, vemos otro ejemplo de esas modificaciones en el capítulo XVII de la Rhetorica christiana, intitulado De explicatione septimi et octavi subiecti, scilicet, de vegetativo et elementativo, cuya traducción es: "Explicación de los sujetos séptimo y octavo, esto es, del vegetativo y del elementativo", que inicia en las últimas dos líneas de la página 71 y continúa en las veinticinco líneas de la página siguiente. En el texto de Remigio Rufo (In rhetoricam isagoge, p. 182-183) se trata primero el sujeto elementativo y luego el vegetativo; en el de Valadés (Rhetorica christiana, pp. 71-72) se procede al contrario. Además, en el tratado seudolulista, ambas partes se encuentran claramente divididas, en el del novohispano aparecen unidos ambos subiecta en un párrafo de 27 líneas que constituye todo el capítulo XVII. Hagamos el cotejo intertextual respectivo.

Como hemos dicho, Valadés copia del original el pasaje relativo al sujeto vegetativo, que se encuentra estructurado en tres partes. En la primera, Remigio Rufo ofrece una definición con ejemplos:

Vegetativum est instrumentum, quo intelliguntur omnia quae animantur: animantia, vegetativa et partes earum, ut sunt Arbores, Herbae, Semina, Flores, Lucus, Gramina. Etiam ligna mortua, Cortices, Foenum, Chordum, Poma et caeteri fructus omnes. 
El vegetativo es el instrumento con el cual se comprenden todas las cosas que tienen vida: los seres animados, los vegetales y sus partes, como los árboles, las hierbas, las semillas, las flores, los bosques, las plantas, además de la leña seca, la corteza de los árboles, el heno, la planta tardía, las frutas, y todos los demás frutos.

Valadés realizó varios cambios. Primero sustituyó est instrumentum por la palabra $s u b$, misma que causó problemas al traductor (vegetativum sub quo intelliguntur...): "Bajo el vegetativo se entienden todas las cosas...", etcétera. En vez de animantia, vegetativa, leyó anima vegetativa, sin coma entre ambas palabras, de manera que en vez de "seres vivos", los traductores entendieron "alma vegetativa", expresión incomprensible si no se encuentra en un contexto apropiado, ya que aparece en la doctrina tomista, pero junto al alma sensitiva y a la racional.

En la segunda parte del pasaje, Remigio Rufo se refiere a la utilidad de todo tipo de vegetales:

Hic nota applicationem ad medicinas simplices copiose: nihil est enim adeo parvum, adeoque vile quod non plurimum commodi habeat, de quo multa se offerant oratori. Et de summis ad infima, et ab imis ad summa ascendere et descendere per gradus causarum oratorem oportet.

Salomon disputavit de cedro Libani usque ad hyssopum parietis, ut est 4 cap. regum 3.

Aquí una nota de la aplicación a las medicinas simples de manera amplia: nada es tan pequeño ni tan bajo que no sea lo más adecuado, acerca de lo cual muchas [razones] se ofrezcan al orador. Y conviene que el orador de lo alto a lo bajo y de lo bajo a lo alto ascienda y descienda de las causas por grados. Salomón disertó acerca del cedro del Líbano hasta el hisopo de las paredes, como en el tercer capítulo de Reyes 3.

En relación con el ejemplo, Valadés tuvo el cuidado de cotejar el texto de la Biblia (1 Reyes, 4.33): Salomon disputavit <super lignis a> [de] cedro, quae est in libano, usque ad hyssopum [parietis] <quae egreditur de pariete, et disservit de Iumentis, et volucribus, et reptilibus et piscibus $>$. En la traducción del Fondo de Cultura Económica (p. 191) se lee: "Salomón 'disertó acerca de los árboles, desde el cedro hasta el hisopo que nace en el muro y también acerca de las bestias, de las aves, de los reptiles y peces'". ${ }^{16}$

${ }^{16}$ Los paréntesis angulares indican supresión y los corchetes, adición. 
Por último, el autor del tratado presenta primero una definición seguida de una clasificación que reproducimos en seguida:

Omnia vegetativa sunt morti obnoxia.

\begin{tabular}{|l|l|}
\hline \multirow{2}{*}{$\begin{array}{l}\text { Vegetativa se habent ut } \\
\text { sunt propositum vel }\end{array}$} & Principale, ut dum dicendum est de balsamo. \\
\cline { 2 - 2 } & $\begin{array}{l}\text { Accessorium ut, dum de arboribus Italiae } \\
\text { dicendum }\end{array}$ \\
\hline
\end{tabular}

Podríamos convertir el cuadro en texto y traducir todo de la siguiente manera:

Toda especie vegetativa es susceptible de perecer. De acuerdo con su propósito, los sujetos vegetales son o bien tema principal, como cuando se debe hablar del bálsamo, o bien accesorio, como cuando se debe hablar de los árboles de Italia.

Valadés reproduce lo anterior como sigue: Omnia vegetativa sunt morti obnoxia, et se habent ut [sunt] propositum principale: ut dum dicendum est de balsamo, vel ut accessorium ut $<$ cum $>$ [dum] de arboribus Italiae, $<$ vel Indiae $>$, donde los corchetes indican adición, y los paréntesis angulares, supresión. En este caso, los cambios afectan poco el contenido, aunque dificultan la lectura.

Luego sigue una definición más y un cuadro clasificatorio:

Herbas dicimus, quaecunque non lignitant, seu ligna producunt. Frutices qui non excrescunt ad iustam mensuram arboris.

\begin{tabular}{|l|l|}
\hline \multirow{2}{*}{ Plantae sunt } & Faecundae \\
\cline { 2 - 2 } & Stertiles \\
\hline \multirow{3}{*}{ Planta triple } & Domestica \\
\cline { 2 - 2 } & Hortensis \\
\cline { 2 - 2 } & Sylvestris \\
\hline \multirow{2}{*}{ Plantarum quaedam } & Masculae, quae citius pullulant \\
\cline { 2 - 2 } & Foeminae, quae maiora folia emittunt. \\
\hline
\end{tabular}


En seguida agregamos una traducción:

Dijimos que las hierbas son aquellas que no son leña o no producen madera. Arbustos los que no alcanzan las dimensiones propias de los árboles. Las plantas se clasifican en fecundas y estériles. Las plantas son de tres especies: doméstica, hortense y silvestre. Algunas de las plantas son machos, las que germinan más rápido, o hembras, las que echan hojas más grandes.

Valadés reproduce sin cambios significativos el texto, a renglón corrido. Luego prosigue con el subiectum elementativum. En la obra seudolulista, el texto es el siguiente (In rhetoricam isagoge, pp. 181-182):

Elementativum est subiectum, quo intelliguntur quatuor elementa simplicia principaliter, et quae ex illis composita sunt, ita ut sensu et vita careant.

\begin{tabular}{|l|l|}
\hline \multirow{2}{*}{ In elementis considerantur } & $\begin{array}{l}\text { Gradus, } \text { ut sunt simplex, compositio, mixtio, } \\
\text { digestio, }\end{array}$ \\
\cline { 2 - 2 } & Situs, Actio, Passio, Quies, Motus. \\
\hline
\end{tabular}

Elementa sunt in duplici differentia, perfecta et imperfecta.

Perfecta, ut ex metallis aurum et argentum, Ex animalibus gressibilibus homo, ex volatilibus Aquila. Imperfecta, ut plumbum, Talpa, Vermes, et similia, secundum gradus suos.

El elementativo es un sujeto en el cual se comprenden cuatro elementos simples principalmente y las cosas que de ellos se componen, de modo que carecen de sentido y de vida. En los elementos se consideran los grados, que son: el grado simple, la composición, la mezcla y el orden, y la situación, la acción, la pasión, el reposo y el movimiento. Los elementos se dividen en perfectos e imperfectos. Los perfectos son aquellos como el oro y la plata, de entre los metales; el hombre, de entre los animales que caminan, y el águila, de entre los volátiles. Los imperfectos, como el pomo, el topo, el gusano y cosas semejantes, según sus grados.

Como hemos venido diciendo, Valadés (Rhetorica christiana, pp. 7172) compone su texto de lo anterior a renglón seguido. Además de adecuar el texto deshaciendo los cuadros, introduce una modificación en la expresión elementativum est subiectum, que se transforma en elementativum est, sub, esto es, sustituye subiectum por sub, que el traductor inter- 
pretó como "bajo el elementativo se entiende [...]". Asimismo, en vez de Situs, Actio, encontramos situs: ut actio, que es algo muy diferente de lo dicho por Remigio Rufo.

En consecuencia, si observamos con atención, podemos notar con claridad los siguientes fenómenos:

1. Valadés copia de manera casi literal el texto del tratado de Remigio Rufo.

2. En el tratado se emplean cuadros que Valadés transforma en texto corrido.

3. Algunas diferencias son simples adaptaciones, esto es, no cambian el contenido.

4. Algunas modificaciones deterioran el texto, sobre lo cual ya nos hemos detenido suficientemente.

En suma, podemos afirmar que Valadés copia el texto de Remigio Rufo y que las modificaciones demeritan el resultado.

Por otra parte, podemos observar que en los capítulos analizados de la Rhetorica christiana se encuentran pasajes extensos que no fueron reproducidos de In rhetoricam isagoge. A primera vista podría pensarse que el propio Valadés los elaboró, contribuyendo de ese modo a enriquecer de manera sensible la versión original del tratado. Hemos visto algunas líneas tal vez escritas por Valadés en relación con las tres fuentes de la confirmación (autentice, similiter y exempli gratia), pero ahora se trata de amplios pasajes. Éstos se encuentran sobre todo en la parte relativa al primer subiectum, esto es, Dios, que ocupa 11 páginas aproximadamente (pp. 56-67), mientras que en Remigio el asunto es tratado en sólo cinco páginas de menor contenido (pp. 186-190).

Ahí Valadés reproduce del tratado seudoluliano los nueve predicados de Dios divididos en tres triadas. Primero, los esenciales: bondad, magnitud y duración (pp. 57-58); en seguida, los causales: potestad, sabiduría y voluntad (pp. 59-61); por último, los finales: virtud, verdad y gloria (pp. 61-63). Valadés procede con cada grupo de la siguiente manera: primero presenta el cuadro con la clasificación de los tres predicados con base, sobre todo, en In rhetoricam isagoge, y en seguida explica en orden cada predicado. Podrá observarse que en las partes explicativas Valadés no se limitó a reproducir su fuente, pues, además de los cambios de detalle, suprimió partes importantes e introdujo pasajes que no se encuentran en el original. Como hemos dicho, esas secciones parecen producto de un verdadero proceso de investigación con abundantes citas, de manera que el texto 
de Remigio Rufo sólo parece haberle servido de esqueleto. Sin embargo, podremos observar que las partes agregadas no son suyas, sino simples copias de otras fuentes.

El procedimiento anterior aparece con claridad en la segunda triada que se refiere a los predicados causales. En primera instancia, Valadés presenta la siguiente clasificación:

\begin{tabular}{|c|l|l|l|}
\hline \multirow{5}{*}{$\begin{array}{r}\text { <Potestas }> \\
\text { Theologice }\end{array}$} & $\begin{array}{l}<\text { Sapientia }> \\
\text { Phisice }\end{array}$ & $\begin{array}{l}<\text { Voluntas }> \\
\text { Mathematice }\end{array}$ \\
\hline \multirow{4}{*}{ [Causalia] } & Potestas Pater & Mens & Punctum \\
\cline { 2 - 5 } & Sapientia Verbum & Mundus & Linea \\
\cline { 2 - 5 } & Voluntas Amor & Nexus & Superficies \\
\hline
\end{tabular}

El cuadro de la retórica seudoluliana es el mismo, excepto porque no incluye la palabra causalia (que ponemos entre corchetes, para indicar que es agregado de Valadés) y porque repite los predicados en la primera fila que aparecen entre paréntesis angulares, para señalar supresión.

En seguida, el franciscano explica ampliamente cada predicado, pero no sigue al autor del tratado, quien es muy parco al respecto. En relación con potestas, Remigio Rufo se limita a desarrollar el tema en cuatro líneas y dos cuadros con sendas clasificaciones de ese predicado. La explicación de Valadés del mismo concepto la desarrolla en 42 líneas. Pero Valadés no es el autor de ese pasaje, sino que toda su información la toma de otras fuentes. Podemos suponer que las primeras veinte líneas (p. 59) provienen de algún manual que no hemos identificado. Las diez siguientes, en cambio, fueron tomadas del De locis theologicis de Melchor Cano, publicado en 1567. Después de haber dividido la potencia en absoluta y ordinaria, Valadés presenta el siguiente texto, al que agregamos corchetes y paréntesis angulares para indicar adición y omisión, respectivamente:

[Sed] quoniam brevis esse cupio, illud statim [etiam] ponendum est, divinae potentiae descriptionem esse duplicem. Nam et generalem quandam intelligimus, quae quoniam lege nulla etiam naturali constringitur a Theologis absoluta vocatur. Et aliam huic subiectam, quae spectat in rerum ordinem praefinitum, ideoque potentiam appellant ordinatam. Atque illa superior definiri sole $<n>t$ circa eas res quas esse non repugnat, quaeve non implicant contradictionem, sic enim loquuntur. Quae autem potentia ordinaria subiecta illi priori quasi generi est, eam definiunt circa ea, quae esse possunt salva 
lege statutisque divinis [vel dic primam esse, qua Deus operatur absque medio causarum secundarum. Secunda, quae ex causis secundis procedit.]

[Pero,] puesto que deseo ser breve, se debe exponer [también] lo siguiente, que la descripción de la potencia divina es doble. Pues bien, entendemos por potencia general aquella que, por no estar constreñida por la ley, ni siquiera por la natural, es llamada absoluta por los teólogos. Y a la otra, subordinada a la anterior, la cual mira el orden de las cosas definido con antelación, y por eso mismo, la llaman ordenada. Pues bien, acostumbra $<\mathrm{n}>$ definir aquella potencia superior en relación con aquellas cosas que existen sin resistencia o que no envuelven una contradicción, y así lo dicen. En cambio, aquella potencia ordinaria está subordinada a aquel precedente género, a la que definen en relación con aquellas cosas que pueden existir sin violar las leyes y los preceptos divinos, [o di que la primera es aquella con la que Dios opera sin el medio de las causas segundas. La segunda es aquella que proviene de las causas segundas.]

El texto que va desde quoniam hasta divinis es copia de un pasaje del segundo capítulo del primer libro de Melchor Cano, ${ }^{17}$ sin modificaciones significativas. En cambio, Valadés agrega el último enunciado indicado en corchetes, el cual copia del texto del In rhetoricam isagoge.

Después del pasaje anterior, Valadés agrega una línea de transición: In rebus vero, etiam potestas invenitur. Nam alia est ("Ahora bien, la potestad se encuentra también en las cosas. En efecto, ésta es:"). Y continúa copiando del cuadro relativo a la potestas dividida en tres tipos. En la Rhetorica christiana aparece de la siguiente manera (indicamos las partes donde hay cambios):

Naturalia est in omnibus, ut potentia maris est submergere naves. Legitima [est, quando id] <et sic $>$ possumus quod iure [non prohibemur] <possumus $>$. Violenta [est], ut si <abutitur $>$ quis virtutibus et viribus [abutatur].

El traductor vertió así el texto:

El natural se halla en todas; por ejemplo, un poder del mar consiste en sumergir naves. El legítimo es cuando podemos hacer algo que no está prohibido por el derecho. El violento es como si, por ejemplo, alguien abusa de sus facultades y fuerzas.

Valadés transcribió el siguiente cuadro sin cambios significativos:

${ }^{17}$ M. Cano, De locis theologicis, p. 13: Ea igitur explicanda quaestione, quoniam [...] statutisque divinis. 
Naturalis, est in omnibus, ut potentia maris est submergere naves.

Potestas Legitima, et sic illud possumus quod iure possumus.

Violenta, vt si abutitur quis virtutibus, et viribus.

Ahí termina la explicación de la potestas y sigue la de la sapientia. Valadés introduce a renglón seguido un amplio párrafo sobre la sabiduría. Pero tampoco toma este pasaje de su fuente principal, sino del Lexicon theologicum de Jean Altenstaig, publicado a inicios del siglo XVI y reeditado en Venecia en 1579. De cualquier modo, al final introduce algunos renglones del In rhetoricam isagoge, como ha hecho en la sección anterior. Nos permitimos hacer un cotejo entre los pasajes del Lexicon de Altenstaig del que copió nuestro autor, en la primera columna, y el pasaje de Valadés, que reproducimos en la segunda. Los paréntesis angulares en el original y los corchetes en la copia de Valadés indican respectivamente las palabras o frases suprimidas y agregadas por el autor novohispano.

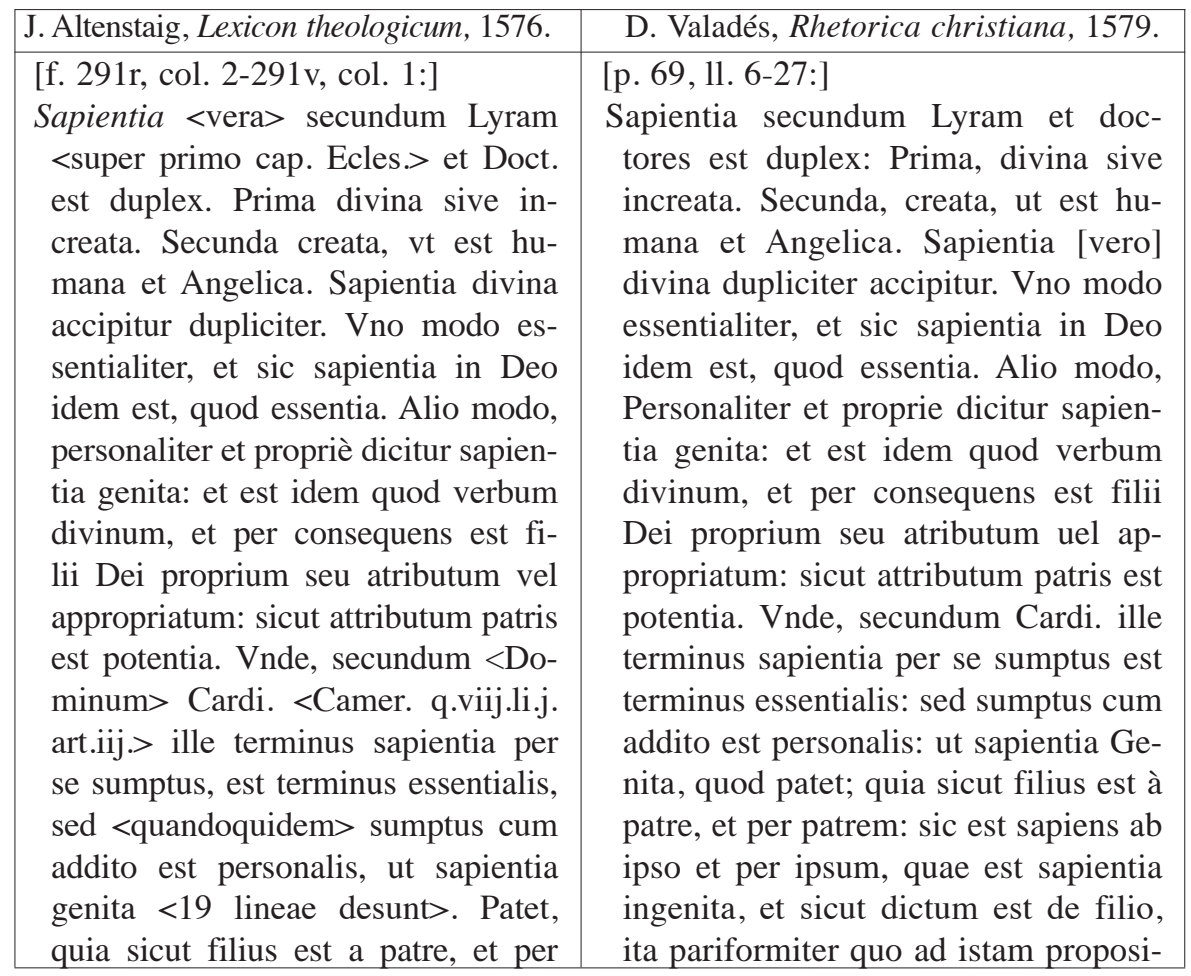


patrem: sic est sapiens ab ipso, et per ipsum, quae est sapientia ingenita, et sicut dictum est de filio, ita pariformiter quo ad istam propositionem potest dici de spiritu sancto. <Haec Aliacen. Vide ad hoc Gabr. di. xxxij.q.j.lib.j.>.

[f. 291r, col. 1-2:]

[...] < Sapientia est $>$ cognitio primarum, et altissimarum causarum. Secundum Alpharabium<: Sapientia> est scientia sempiternorum. <Cicero in lib. Tuscul. Quaest. ita sapientiam diffinit: Sapientia est $>$ rerum divinarum et humanarum scientia, cognitioque, quae causa cuiusque rei sit ex quo <efficitur>, ut divina imitetur, humana omnia virtute inferiora ducit $<$, secundum Thom. secunda secundae quaest.xxiij>. Sapientia qua formaliter sapientes sumus, est quaedam participatio diuinae sapientiae, quae Deus est. $<$ Et $>$ omnis sapientia est scientia, inquantum est de conclusionibus. Sed differt a caeteris scientiis in quantum est de principiis, <secundum beatum Thom. Prima ij.q.lvij.art.ij.>

A continuación presentamos la traducción que integra ambos textos, indicando también en este caso en paréntesis angulares las omisiones, y en corchetes, lo que agrega Valadés:

Según <el Comentario de Nicolás de> Lyra <al primer capítulo del Eclesiástico, 1472> y los Doctores, la sabiduría es doble. La primera, divina o increada; la segunda, creada, de modo que es humana y angélica. La divina se recibe de dos modos. De un modo, en esencia, y así la sabiduría que está en Dios es lo mismo que la esencia. Del otro modo, personal y propiamente se dice sabiduría engendrada, y es lo mismo que verbo divino y en consecuencia es lo propio, el atributo o lo apropiado del hijo de Dios, así como lo apropiado del padre es la potencia. De ahí, según el divino cardenal de Cambray, q. viii, li. i, art. iii,* el término sabiduría, tomado por sí mismo, es término esencial; pero tomado en relación con otra cosa, es personal, como la sabiduría engendrada $<$ faltan 15 líneas> lo que es claro, pues así como el hijo existe por causa del padre y por 
el padre, así es sabio por causa de él y por él, la cual sabiduría es ingénita, y así como se dijo acerca del hijo, de la misma manera que en esta proposición puede decirse del Espíritu Santo. <Estas cosas afirma Pierre d'Ally. Véase sobre esto, Biel, di. xxxii, q. i, lib. i>** II En cambio, la sabiduría creada es el conocimiento de las causas primeras y más elevadas. [O] según Al-Farabi [en su libro De la división de la filosofía] es la ciencia de las cosas eternas. <Cicerón, en su libro Disputas tusculanas, IV 57, define la sabiduría de esta manera:> "Sabiduría es la ciencia de las cosas divinas y humanas, y el conocimiento de la causa de cada cosa", de lo cual se deduce que, como imita las cosas divinas, considera todas las cosas humanas inferiores a la virtud", $<\mathrm{y}>$ según $<$ Santo Tomás II-II, quaestio 23:> "Sabiduría, porque formalmente somos sabios, es cierta participación de las sabiduría divina, la cual es Dios". $<Y>$ [Santo Tomás, 22, q. 23:] "toda sabiduría es ciencia en cuanto trata de conclusiones, pero difiere de otras ciencias en cuanto trata de principios" <según Santo Tomás, I 11, q. lvii, art. 11>.

* Pierre d'Ailly (1351-1420), en sus Quaestiones Magistri Petri de Alliaco cardinalis Cameracensis super primum terium et quartum libros sententiarum, publicado en París hacia 1499. ** Gabriel Biel (1410-1495), Selección o resumen de los IV libros de las Sentencias del Maestro, publicado por primera vez en 1501.

A renglón seguido, Valadés continúa copiando en la página 60 lo siguiente:

J. Altenstaig, Lexicon theologicum 1576.

[f. 291r, col. 2:]

Sapientia differt à scientia. Quia sapientia est rerum diuinarum cognitio. Scientia vero humanarum. Quare Aug. <super i. Cor.12.> ait: Sapientia est in contemplatione aeternorum. Scientia vero in occupatione temporalium. Item <Augustinus libr. de Trinit.> Haec est sapietniae et scientiae recta distinctio, vt ad sapientiam pertineat, aeternarum rerum cognitio intellectualis. Ad scientiam vero, temporalium rerum cognitio rationalis.

In rhet. isagoge, p. $188+1$ Cor. 1, 27$29+$ In rhet. isagoge, p. 188:

Sapientia divina est per se et primo sapientia veri Dei.

$<27-29$ : Sed, quae> stulta < sunt mundi $>$ elegit Deus, ut confundat sapien-
D. Valadés, Rhetorica christiana, 1579. Sapientia [etiam] differt à scientia, quia sapientia est rerum divinarum cognitio. Scientia vero humanarum. Quare Aug. ait sapientia est in contemplatione aeternorum; scientia vero in occupatione temporalium. Idem, haec est sapientiae et scientiae recta distinctio: ut ad sapientiam pertineat, aeternarum rerum cognitio intellectualis. Ad scientiam vero, temporalium rerum cognitio rationalis. \| [Tum etiam,] divina sapientia est primo et per se sapientia veri Dei. [Quare arcanorum Dei conscius, ait,] elegit Deus stulta ut sapientes confunderet, et infirma mundi elegit Deus, ut confundat fortia, et ignobilia mundi, et contemptibilia elegit Deus, et ea quae 
tes, et infirma mundi elegit Deus, ut confundat fortia, et ignobilia mundi et contemptibilia elegit Deus, et ea quae non sunt, ut ea quae erant destrueret, ut non glorietur omnis caro in conspectu Dei.

Sapientia est emanatio claritudinis omnipotentis Dei: et est imago bonitatis eius. non sunt, ut ea quae sunt destrueret, et non glorietur omnis caro in conspectu eius: [Et] sapientia est emanatio claritudinis omnipotentis Dei: et est imago bonitatis eius.

Además, la sabiduría difiere de la ciencia en que sabiduría es conocimiento de las cosas divinas y la ciencia, en cambio, de las humanas. Por esta razón, Agustín $<1$ Cor. 12> afirma que la sabiduría consiste en la contemplación de las cosas eternas, la ciencia, en cambio, en la ocupación de las temporales. También $<$ Agustín, en su libro Acerca de la trinidad>. Esta es la distinción correcta entre sabiduría y ciencia, de modo que pertenece a la sabiduría el conocimiento intelectual de las cosas eternas; a la ciencia, en cambio, el conocimiento racional de las cosas temporales. II Asimismo, la sabiduría divina es, en primer lugar y per $s e$, sabiduría del verdadero Dios. [Por esta causa, conocedor de los misterios de Dios] dice, "Dios eligió la necedad < del mundo $>$ para confundir a los sabios, y eligió Dios la flaqueza del mundo para confundir a los fuertes, y lo vil y lo despreciable del mundo y lo que no es nada, para destruir lo que es, para que ningún hombre se glorie ante Dios. [Y] la sabiduría es emanación de la claridad de Dios omnipotente, y es imagen de su bondad.

Como podemos observar, Valadés recoge textos de otras fuentes y las integra entre las definiciones del tratado seudoluliano, de donde obtiene una mezcla singular. Veamos cómo procede en el caso del Lexicon theologicum. En éste se encuentran once entradas para la palabra Sapientia. ${ }^{18}$ Valadés reproduce varios pasajes de las últimas tres, que se encuentran en las páginas 291 y 292 de la edición de 1579. Sin embargo, no lo hace de manera ordenada y clara, sino - como ya hemos dicho- mezclando diferentes secciones de manera confusa.

${ }^{18}$ La primera trata sobre el sentido del término en general, donde se menciona a los siete sabios. El segundo, sobre los cinco modos en que se obtiene la sabiduría. La tercera entrada se refiere al cuarto modo de adquirir la sabiduría, en este caso por inspiración divina. La cuarta trata sobre cuatro modos de adquirir la sabiduría. La quinta, sobre la sabiduría divina. La sexta, sobre la sabiduría de los cristianos. La séptima, sobre la sabiduría evangélica. La octava, sobre la sabiduría diabólica. La novena, sobre las definiciones de sabiduría de los filósofos. La décima trata sobre la diferencia entre sabiduría y ciencia. La undécima, sobre la clasificación de la doble sabiduría: divina y humana, y la adquisición de la sabiduría divina de dos modos. 
Valadés empieza copiando la última entrada (la 11), la cual trata de la división de la sabiduría en divina o increada y humana o creada; pero no toma el texto completo, sino sólo las primeras 13 líneas y las últimas 5, dejando las 19 de enmedio, de modo que tenemos un texto mutilado de una parte esencial, donde se explica en qué consiste la diferencia entre los dos tipos de sabiduría. Primero se trata la divina, luego la humana (que también es la del Hijo). Así, el Hijo de Dios no puede ser sabio por la sabiduría creada por sí misma (puesto que el Hijo no es por sí mismo), pero sí mediante la creada, la cual proviene del Padre. Asimismo, el Hijo es sabio tanto por la sabiduría increada en sí misma o mediante ella. En seguida se explica las razones de lo anterior: "es claro", puesto que el Hijo existe por el Padre (causa eficiente) y mediante él (per modum). Valadés se limita a copiar esto último, y el contenido resulta incomprensible.

Luego, se fija en la entrada 9, que contiene definiciones de sabiduría por parte de los filósofos, y se decide a reproducirla, pero sólo se interesa por las últimas 14 líneas y deja las primeras 11, como si continuara con la sabiduría humana o creada. Por eso el texto resulta absurdo, pues en la traducción del FCE se dice que: "la sabiduría creada es el conocimiento de las primeras y últimas causas [...] es la ciencia de las cosas sempiternas dado que es la ciencia de las cosas divinas y humanas". Entonces, nos encontramos ante una confusión, pues al principio se había diferenciado la sabiduría creada de la divina, aunque la exposición es clara en el Lexicum de Altenstaig.

En seguida, Valadés prosigue copiando las 9 primeras líneas de la siguiente entrada, la 10, donde trata de la diferencia entre sapientia y scientia, y decide dejar las 19 restantes. Las últimas líneas son una mezcla de partes del texto del tratado In rhetoricam isagoge y de un pasaje de la Primera carta a los corintios 1,27-29, insertándose esta última en medio de aquella. Las líneas de la Biblia nada tienen que ver con el asunto tratado de la sabiduría divina.

Por tanto, podemos observar que la explicación de Valadés sobre la sapientia proviene de varias fuentes (un manual, una obra de consulta y el Nuevo Testamento). Nada de lo escrito es obra del propio franciscano. Además, las combinaciones que elabora son poco afortunadas. Al final tenemos una versión poco clara e incompatible con el asunto central.

Valadés continúa (siempre a renglón seguido) con la voluntas, a la que dedica 40 líneas, mientras que Remigio Rufo la trata en ocho, repitiendo el mismo procedimiento que antes hemos descrito. La mayor parte de 
esta sección es una reproducción de tres entradas de la voz Voluntas del Lexicon theologicum, y sólo las últimas cinco líneas del In rhetoricam isagoge. En este caso, la reproducción es más ordenada, pues primero copia de la primera entrada de Voluntas, al final de la página $347 \mathrm{v}$, y continúa copiando de las siguientes dos entradas, como podemos observar en nuestra reproducción del final de la página señalada (aquí abajo), y la siguiente del Lexicon (p. 191), indicando con sombreado las partes que Valadés no copió, y en subrayado los lugares donde hizo cambios.
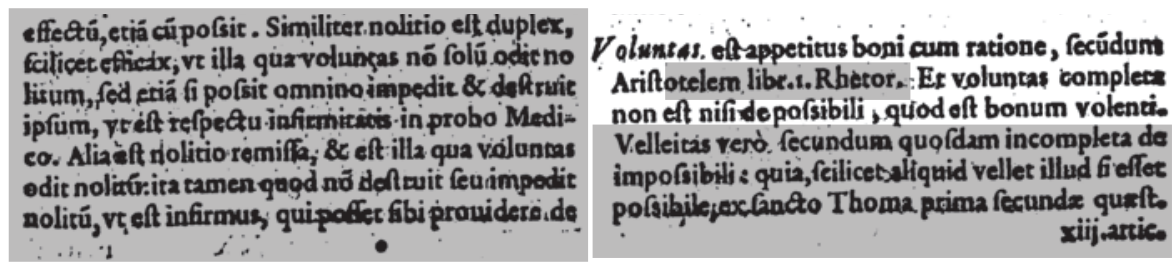

J. Altenstaig, Lexicon theologicum, p. 347v.

Valadés deja algunas palabras y pasajes de las partes copiadas del Lexicon de Altenstaig con el propósito tal vez de ahorrar algún espacio. De la primera entrada se limita a copiar la definición y su clasificación, y deja otras explicaciones o usos particulares que ocupan la mayor parte. De la segunda entrada sólo copia lo que le pareció más significativo en relación con la voluntas divina, esto es, su clasificación en dos tipos y alguna consideración de Gabriel Biel, aunque no reproduce la parte relativa a la voluntas divina como causa prima, según Bonaventura. En fin, de la tercera entrada, relativa a las acepciones de voluntas en las Sagradas Escrituras, copia lo esencial, aunque aquí realiza más cambios en el texto. Habrá que señalar que Valadés pone en los márgenes todas las referencias a los autores que en el Lexicon aparecen en el cuerpo del texto. No copia nada de las quince entradas siguientes, de modo que Valadés ofrece una selección parcial de un conjunto claramente sistematizado por Altenstaig. Habrá que observar que, en el caso de la $s a-$ pientia, el franciscano empieza a copiar partes de las acepciones finales del Lexicon; ahora procede al contrario. Al parecer lo hace de manera atropellada e irreflexiva, pues no se percibe que su intención hubiera sido rescatar lo más importante o mejorar su fuente.

Ya observamos la mezcla incoherente que el franciscano hace del segundo predicado causal. Ahora, al abordar el tercer predicado, su 
xïj_artic.v. Et nomen volưntas (ve ftribit Gabrat dift.xxxviij.quzeft.vnica, artic.j.hbr.ij.) aliquando accipitur pro potentia appetitiua rationali, id eft pro anima rationali, nata obiectum f́bi per rationem oftēfum appetere vel refutare. Et fic potèft aco cipi Luc.1. Et in terra pax homimibus bonx volun ratis, id eft voluntatis bene habituatz: Aliquando accipitur pro actu appetitiuo, fälicet pro ipfo velle vel nolle. Sic dicitur 1.ad Timoth.4. Voluntas Dei eft fanctificatio veftra, id eft hoc vult Deus, fiue hoc eft velle Dei,fanctificatio veftra.Et Luc.12.Seruus qui cognouit voluntatem Domini fuir ; 8 non fecit fecundum voluntatem eius, vapulabit multis. Accipitur quädog; pro obiecto volizo, vt ibi: Non mea, fed tua voluntas fiat. Matth.26. Et voluntas quadam eft increata \& diuina, quadam creata \& humana. Videamus primo de voluntate increata, pofted de creata.

$V_{\text {olwntas diuina quandoque accipitur propriè pro }}$ diuina effentia, qua Deus vult aliquid fieri vel non fieri, sc tunc fignat diuinum beneplacitum, quod non eft aliud quàm Deus volens, ve dicit Dominus Cardinalis Cameracenfis quxef.xiiij. artic.j. libr.j. Alio modo improprit, tropice, vel metaphorice, pro aliquo habente aliquo modo ordinem ad diuinam voluntatem: \& fic fecundú Aliacenfem vbi fiv pra fupponit non pro beneplacito vel voluntate Dei, fed pro aliquo alio, quod eft eius fignum. Et fecundum hoc communiter diftinguitur in voluncatem beneplaciti, \& voluntatem.figni. De qua plura videro Gabriëlem lea.Ixviij. \& lxix.canon.

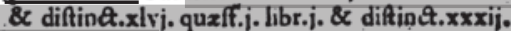
quxaft.ij.libr.j. dicit quod voluntas diuina eft concors \& mutua charitas fiue dilectio, \& amor iocun dus \& mutuus, communis patri \& filio \& fpirituifancto. Nec plus diftinguitur ab effentia diuina communi tribus perfonis, quàm eflentia à feipG, fed funt idem omnibus modis. Hac voluntas diuina, fola eft prima regula omnis iuftitiz, \& $\mathrm{ed}$ quod vult aliquid fieri, iuftum eft fieri, \& ed quod rult aliquid non fieri, non eft iuftum fieri. Vide ad hoc Cameracenfem quaft.xiij. artic,ij. \& Gregor. Item S.Thom.quzft.j.do potentia, artic.v.\& quxft.iij.de creatione, artic.xv. \& vj. Hac voluntas diuin, ve fcribit fanctus Bonauentura diftin.xlv. artic.ij.quxft.ij.libr.j. eft caufa prima \& yniuçralifsima \& actualifsima : ideo potelt in totum effectum, \& in rotam rei fubftantiam etiam fine adminiculo alterius caufę, necaliqua caufa poreft aliquid vel modicum fine ipfa : \& ideo necefte eft quod ipla fit caufa immediata in omni actione \& re. De quo aliass; \&c.

Volwntas Dei diverfimodd accipitur in fcriptura.

Vnde Magifter libr.j. diftinct.xlv. cap. vij. Sacra feriptura, inquit, de voluntate Dei variis modis loqui confuetuit, 8 tamen non eft Dei voluntas diverfa: fed locutio diuerfa eft de voluntate Dei, quia nomine voluntatis diuerfa accipit. Nam volunras Dei verct \& proprit dicitur, qux in ipfo eft, \& ipfius effentia eft. Et has vna eft, nec multiplicizatem recipit. Hzc Magifter. Vnde folet voluntas Dei diftingui in voluntatem beneplaciti, $\alpha x$ in voluntatem figni . Voluntas benoplaciti duplex eft, fälicet, voluntas antecedens \& cónfequens." Voluatas figni quintuplex; fcilicet, prohibitio,prest coptio, confilium, impletio, fiue operatio . Permifsico, hoc eft, ille terminus voluntes aliquando idem eft quod prohibitio. Quandoque idem fignificat quod prexeptum. Vnde patet quod hacdiltin ctio non elt diftinctio rerum, fed eft diltinç jo huins vocabuli voluntas, fecundum diuerfas fuas fignificationes, quibus accipitur in fcriptura, vit vult Magifter. Ex proprit accipiendo vocabulum volune luntas, dicit folùm voluntatem beneplaciti confequertem . De hoclegere potes latius Oabriēlem lea. Ixviij.canonis. Occam diftind̂. xlv. fibi.j.j. \&c Gabr.diftin \&.xlvj. libr.j. Dominum Cardinalem Camerac.quart.xiij.lib.j.\&zc.

glumtas Dei antecedens, non êt aliquid in Ded quomodocunque diftinctum à voluntate Dei con:fequente : fed ille terminus voluntas antecedens, ẹft terminus connotatiuus, fignificans multa, Deü filicet \& creaturam. Et potelt fic defcribį Voluntals antecedens eft voluntas diuina, dans alicui aritecedentia ad cōfequendum aliquid cum przcepto \& confilio exequendi, fine reuelatione contrarij paraca ei coagere fi velit. Et velle antecedenter, eft feu dicit Deum dare antecedentia (hoc eft neceffaria) ad aliquod praceptum vel confilium exequene. dú. Et Deus antecedéter vult omnes, viatoress iuftל viuere, quia dat potentiam, intelleèü, \& affedum cum przcepto : nec ideo precipit bona, quia bona fint, vel prohibet mala, quia mala fint: fed ideo hęe bona funt, quia pracipiuntur: \& mala, quía prohibentur.Irem Deus non vult antecedenter aliquemt peccare, quia nee przcipit nec cöfulit peccare. Itrem Deus non voluit Abraham antecedenter immolart filium,quia licłt dederit potétiam immolandi cum prescepto, tamen oppofitum'reuelauit, Item Deus vilt prafcitos faluari. Patet difcurrendo omines particulas. Sed non vule damones vel damnatos Caluari voluntate antecedente, quia noh vult illis coagere ad opera meritoria, quibus confequantur. falurem, neque fine méritis conferre falutem - Sed valt omnes viatores faluos fieri voluntate antecedente, quia dedit potentiam merehidi cum pirzcis pto; paratus coagere fi velint, nec reuelat contrarium. De quo vide fanctum Bonauent. dift.xivi: quxift.j.lib.j. Vet valt omnes homines faluos fier roluítate conditionata, fi non peccautrint mortaliter, vel fi penituetint. Poteft autem illa tuetoritas Apoftoli 1.2d Timoth.2. Deus vult omines faltos fieri, exponi de voluntate fight, vt intelligatur, vult, id eft przclpit vel obligat vt ormnes fllui fiant. Si verd aucturitas exponitur de voluntate beneplaciti, poteft ittelligi de volutute antectedenre. Si exponitur de volítate benéplaciti ptoprit di Ata, debetintelligi, ficut dicit Magift.id eft nulli Ela uaptur, nifi quos Deus vult faluari. Ideo orädus eft vi velit,ficut \& illud: Uluminat omnê hominé venienté in húc mundú. Poteft etiả exponi nó fecun-: dă diftributioné proprił dietá, fed fecundú diftribù tione actómodarin, ita quod ly homines diftribuicurvir pró fingulis generfi, fod pro generibus fingu lợum, id eft de onıni genere vult a liquos faluari, $\&$ de Otzeis \& Latinis, de Przlatis \& fubditis, \& do ómni gente. Ideo dicit Apoftolus pro örimibus effets $\mathbf{X X} 2$ orandums 
procedimiento es mejor, aunque también realiza algunas modificaciones que a veces oscurecen el sentido. Por ejemplo, en las primeras líneas de la segunda entrada se lee: Voluntas divina quandoque accipitur propriè pro divina essentia, qua Deus vult aliquid fieri vel non fieri, et tunc signat divinum beneplacitum. Valadés empleó la palabra ostendit en vez de signat. La versión de los traductores del Fondo de Cultura Económica, por ello, es poco clara:

La voluntad divina alguna vez se toma por la esencia divina, por la cual Dios quiere que algo se haga o no se haga, y entonces muestra su divino beneplácito.

Lo que el texto dice es algo muy diferente:

Voluntad divina a veces se emplea en su acepción propia de esencia divina, en cuanto Dios quiere que algo se haga o no se haga, y entonces designa un deseo divino.

Los cambios en la tercera entrada afectan a veces el sentido y afean el estilo. Las líneas iniciales se pueden entender de la siguiente manera:

Voluntad de Dios tiene diversas acepciones en las Sagradas Escrituras, para lo cual véase el libro I, distinción 45, capítulo 7 del Maestro. Las Sagradas Escrituras - dice - hablan con frecuencia de la voluntad de Dios de varias maneras, y a pesar de ello la voluntad de Dios no es diversa, sino que la locución "voluntad de Dios" es diversa, en cuanto el nombre voluntas tiene acepciones diferentes, pues se dice "voluntad de Dios" en sentido recto y propio a aquella que está en él mismo y es su esencia. Y ésta es una y no múltiple. Hasta aquí el Maestro. De allí se acostumbra dividir la voluntad de Dios en voluntad del deseo y voluntad del signo.

Como Valadés prefiere unde en lugar de et tamen, el sentido cambia: "por ello, no es diversa su voluntad..."; es evidente que no se trata de una consecuencia, sino de una explicación. Luego, Valadés transforma la frase Vnde solet voluntas Dei distingui, en distingui tamen... solet. Pero no se trata de una oposición (tamen), sino de una consecuencia (unde).

Al final, Valadés termina con un párrafo modificado del In rhetoricam isagoge. En seguida incluimos el pasaje original y la copia de Valadés con el fin de observar las modificaciones que introduce el autor novohispano: 
Boetius de consol. Duo principia actuum humanorum, videlicet voluntas et potestas. Sapientia autem media est, quia alia duo omnino videntur caeca, nisi intercedat lumen sapientiae (In rhetoricam isagoge, p. 189).

Unde, integerrimus philosophus Boet. colophonem his apponens, dicit, esse duo principia actuum humanorum, videlicet voluntatem et potestatem. Quibus sapientia mediat, sinequa duo alia omnino videntur caeca nisi intercedat lumen sapientiae (Valadés, Rhetorica christiana, p. 61).

Los cambios parecen no afectar el sentido del texto. Sin embargo, tal vez el franciscano leyó colophonem en vez de de consol., pues no parece que haya recurrido a otra fuente. $\mathrm{O}$ tal vez quiso corregir el texto, aunque con graves resultados, como sucede con frecuencia.

Hemos analizado sólo la segunda triada del sujeto "Dios", relativa a los predicados causales (potestas, sapientia, voluntas), que se expone en casi tres páginas. Valadés desarrolla la tercera triada sobre los predicados finales en cinco páginas y media, mientras que Remigio Rufo sólo en una y media. Procede del mismo modo que hemos descrito. Ahora el copista se basa más ampliamente en el Lexicon de Altenstaig, aunque no deja de introducir en medio de los párrafos algunas líneas del tratado del desconocido Remigio Rufo, hasta la página 190. Después, en las siguientes siete páginas de su obra, Valadés sigue copiando casi exclusivamente de las páginas de ese tratado, hasta llegar al sujeto instrumentativo. Sin embargo, contra lo esperado, ya no prosigue con los praedicata respectiva, o relativos, que también son nueve y están distribuidos en tres triadas: diferencia, concordia y oposición; principio, medio y fin, y mayoridad, igualdad y minoridad. Rufo les da la misma extensión a éstos que a los predicados "en general" o absolutos. Pero Valadés ya no copia más. Deja a la mitad su trabajo, como si ya hubiera terminado o estuviera agotado. Remigio (o Lavinheta) continúa con las quaestiones. Este asunto lo aborda Valadés en las últimas páginas de su Rhetorica christiana. Pero para tratar este punto ya no le interesa más el tratado De rhetoricam isagoge. Es muy probable que haya encontrado otro texto. Por el momento, vuelve a las partes de la retórica, luego de haber tratado acerca de los subiecta y de los praedicata de manera amplia, aunque su trabajo fue incompleto e inadecuado.

\section{Conclusiones}

De acuerdo con el análisis intertextual que hasta aquí hemos realizado, podemos afirmar que en los capítulos estudiados (hipertexto), Valadés 
hizo una mezcla de pasajes de varias obras (hipotextos) con resultados, desde nuestro punto de vista, poco satisfactorios. Esta forma de trabajo no es accidental, sino bastante extendida a lo largo de la obra.

Podría parecer que lo aquí expuesto no es ninguna novedad, pues resulta evidente que la Rhetorica christiana es una transcripción de diferentes textos. Además, no se trata de un fenómeno aislado, sino de algo común en la época. Hay muchos otros ejemplos, como el de Ludovico Dolce, un conocido escritor del siglo XVI, que publicó diálogos en italiano, traducidos de tratados en latín, a veces sin mencionar su fuente. Así, nunca dice que su Dialogo per accrescere la memoria sea una traducción y adaptación del Congestorium memoriae de Johannes von Romberch. Por su parte, Valadés reprodujo amplios pasajes del tratado en latín, apoyándose en el diálogo en italiano, para elaborar los capítulos sobre la memoria. ${ }^{19}$ A pesar de que es evidente que se trata de una compilación, de un extracto de varias obras, al parecer muy pocos estudiosos modernos de Diego Valadés se han dado cuenta de ello, y la gran mayoría continúa atribuyéndole al novohispano virtudes y defectos que deben ser adjudicados a otros. ${ }^{20}$

En cuanto a su contenido, podría pensarse que si Valadés transcribió esos textos, es porque estaba de acuerdo con su contenido, esto es, que asumía como propias las doctrinas que encontraba en las fuentes reproducidas. Lo anterior puede ser cierto en general, pero no en el caso específico del franciscano, pues no se trata de la copia de una obra, sino de varias, con orientaciones diversas.

De cualquier modo, lo importante de todo ello son dos cosas. Primero, muchas hipótesis y discusiones que se han suscitado en torno a Valadés se desvanecen, se debilitan o se eliminan. Veamos algunos

${ }^{19}$ A lo dicho al profesor podríamos agregar que una parte amplia del In rhetoricam isagoge es la adaptación de una obra de Angelo Poliziano.

${ }^{20}$ Existen también atribuciónes a Valadés de expresiones que en realidad son de Fray Luis de Granada: "Nuestra obra, escribe Valadés, al entregar esta reflexión, está en que, siempre que hayamos desarrollado una argumentación o explicado un misterio, en cuanto es posible dirijamos eso mismo que dijimos, al objetivo de nuestro oficio, es decir, a la formación en la vida cristiana o a conmover piadosamente a las almas". El pasaje proviene del capítulo XIII del libro VI dedicado a la actio (Granada, 1999, p. 524). Lo anterior reafirma lo que hemos dicho, que el texto de Valadés debe someterse a una seria revisión crítica que ponga atención en las prácticas intertextuales, ardua labor que está llevando adelante el doctor Julio Pimentel Álvarez, de la UNAM, en una nueva traducción de toda la Rhetorica christiana. 
ejemplos. Hay autores que consideran que su latín es pésimo y otros, por el contrario, afirman que no sólo está bien escrito sino incluso que es elegante (cf. Chaparro, 2002, p. 632). Lo anterior ya no tiene validez si no se demuestra primero que se parte de un texto auténtico, no de una copia o transcripción. Asimismo, los estudiosos en general concuerdan en la importancia de los capítulos dedicados a la memoria y a la nemotecnia en la Rhetorica christiana. Hay también quienes consideran que Valadés fue manifiestamente seguidor de Raimundo Lulio, como hemos mostrado al comienzo de este trabajo. Muchas otras afirmaciones se dan en el mismo tono sobre Diego Valadés y su retórica. Si lo que hemos señalado en las páginas anteriores es cierto, por lo menos debemos reconsiderar lo que se ha dicho sobre su obra.

En segundo lugar, en cuanto a su supuesto lulismo, que es uno de los temas de debate, reflexionemos si ello es cierto. Esto pudo haber sucedido sólo si Valadés leyó o estudió sus fuentes en las escuelas del Nuevo Mundo, bastante escasas. Sobre esto, empero, no se puede dar con seguridad una respuesta afirmativa. Lo que podemos observar es que el tratado In rhetoricam isagoge no se encontraba en ninguna biblioteca del Nuevo Mundo. En cuanto al Lexicon theologicum de Altenstaig, éste sí aparece en las listas de la Biblioteca del Colegio Imperial de Santa Cruz de Tlatelolco, pero es una versión de 1580, que no pudo leer Valadés. ${ }^{21}$ En cambio, si su trabajo lo realizó en la biblioteca del Vaticano, donde podía haber encontrado una enorme cantidad de fuentes al respecto, entre ellas las de la escuela lulista, podemos afirmar que se hizo lulista, en caso de que ello hubiera sucedido, sólo después de su contacto con esas obras. Y ese contacto pudo darse durante su estancia en Roma, a partir de 1575, año de su traslado al Vaticano. Sea lo que fuere, la copia parcial y maltrecha de un tratado de un seguidor de Raimundo Lulio no es una prueba suficiente que permita considerar a Valadés como un ejemplo de lulismo en la Nueva España.

${ }^{21}$ Las afirmaciones anteriores se basan en el libro de Miguel Mathes, 1982. Osorio Romero (1980, p. 50) observa que "La BNM conserva un ejemplar de la primera edición de Lisboa, en la remesa de 1584", es decir, cuando muy probablemente Valadés ya había muerto. A pesar de lo anterior, el propio estudioso afirma que Granada influyó en Valadés en la Nueva España. 


\section{BIBLIOGRAFÍA}

Fuentes

Altenstaig, Jean, Lexicon theologicum: complectens vocabulorum descriptiones, diffinitiones et interpretationes, quae sunt scholae theologicae propria, ab ea ad commodiorem doctrinam vel excogiata, vel a profanis authoribus ad vsum suum traducta, Venetiis, apud Haeredes Melchioris Sessae, 1579.

De Lyra, Nicolaus, Postilla litteralis in vetus et novum testamentum, Konrad Sweynheym und Arnold Pannartz, 1472. Vol. 1: Genesis-Paralipomena; vol. 2: Esdras-Ecclesiasticus; Vol. 3: Isaias-Machabaei; vol. 4: Evangelia; vol. 5: Epistula Pauli-Apocalypsis.

CANO, Melchor, De locis theologicis. Libri duodecim, Salmanticae, Mathias Gastius, 1563.

Dolce, Lodovico, Dialogo di M. Lodovico Dolce, nel quale si ragiona del modo di accrescere e conseruar la memoria, in Venetia, appresso Gio. Battista, et Marchio Sessa fratelli, 1562.

GrANADA, fray Luis de, Retórica eclesiástica, 2 vols., traducción al español de José Climent, ed. de Álvaro Huerga, Madrid, Fundación Universitaria Española, 1999.

Mathes, Miguel, Santa Cruz de Tlatelolco: La primera biblioteca académica de las Américas, México, Secretaría de Relaciones Exteriores, 1982 (Archivo Histórico Diplomático Mexicano. Cuarta época, 12).

SoÁREz, Cypriano, De arte rhetorica libri tres ex Aristotele, Cicerone et Quintiliani praecipue deprompti. Conimbircae [sic]: apud Ioannem Barrerium, 1562. Se ha consultado la siguiente edición: Hispali, Ex officina Alphonsi Escrivani, Expensis Andreae Pescioni, cum facultati, 1569 [disponible en linea: http://gallica.bnf.fr/ark:/12148/bpt6k838952/f16.image.r=.langES].

RAIMUNDO Lulio, Raemundi Lulli [...] in Rhetoricen Isagoge perspicacibus ingeniis expectata [Paris, Josse Blade], 1515.

_, Raymundi Lulli Opera ea quae ad adinventam ab ipso artem universalem, scientiarum artiumque omnium brevi compendio apprehendarum pertinent... I accessit Valerii de Valeriis, Venecia, Argentoratum, 1617, pp. 178-223.

Romberch, Johannes von, Congestorium artificiosae memoriae, Venecia, in aedibus Georgii de Rusconibus, 1520.

VALADÉs, Diego, Rhetorica christiana ad concionandi, et orandi usum accommodata utriusque facultatis exemplis suo loco insertis, quae quidem ex indolum maxime deprompta sunt historiis und praeter doctrinam summa quoque delectatio comparabitur, Perusa, Petrus Jacobus Petrutius, 1579.

VALAdÉs, Diego, Retórica cristiana, México, FCE, 1989.

\section{Estudios}

BÁEz RuBí, Linda, "Variaciones sobre un tema luliano: La figuración del ars magna sciendi", en Arte y Ciencia. XXIV Coloquio Internacional de Historia del Arte, México, 2002, pp. 549-576. 
-, Mnemosine novohispana. Retórica e imágenes en el siglo XVI. México, UNAM, 2005 (Estudios de Arte y Estética, 58).

Beuchot, Mauricio, "Retórica y lulismo en Diego de Valadés", Estudios Lulianos, 32, 1992, pp. 153-161.

_, "Un ejemplo de la retórica en la escuela lulista: Remigio Rufo o el vértigo de la omnisapiencia”, en Iztapalapa, 41, enero-junio, 1997, pp. 167-180.

-, "Un caso de la escuela lulista, Remigio Rufo o el arte de la omnisapiencia", en La retórica como pragmática y hermenéutica, México, UNAM, 1998, pp. 63-78.

_, Retóricos de la Nueva España, 2a ed., México, unAm, 2010.

Chaparro Gómez, César, "Diego Valadés, ¿el primer rétor de la Nueva España?", en José María Maestre Maestre, Joaquín Pascual Barea y Luis Charlo Brea, Humanismo y pervivencia del Mundo Clásico. Homenaje al Profesor Antonio Fontán (Alcañiz, 8 al 13 de mayo de 2000), Alcañiz / Madrid, Instituto de Estudios Humanísticos / Ediciones del Laberinto, 2002, vol. III.2, pp. 631-646.

_, "Retórica y libros de caballerías. La presencia de exempla en la Rhetorica christiana de Diego Valadés", Cuadernos de Filología Clásica, Estudios Latinos, 24/2, 2004, pp. 257-292.

_, "Retórica, memoria y diagrama en la Rhetorica christiana de Diego Valadés", Humanistica Lovaniensia, 57, 2008, pp. 185-208.

Domínguez Reboiras, Fernando, "La recepción del pensamiento luliano en la península ibérica hasta el siglo XIX. Un intento de síntesis", en Revista de Lenguas y Literatura Catalana Gallega y Vasca, 15, 2010, pp. 361-385.

GenetTe, Gérard, Palimpsestos. La literatura en segundo grado, Madrid, Taurus, 1989.

OSORIO ROMERo, Ignacio, Floresta de gramática, poética y retórica en Nueva España (1521-1767), México, UnAM, 1980 (Cuadernos del Centro de Estudios Clásicos, 9).

Pereira, Michela, “L'uso del 'Panepistemon' del Poliziano nella Isagoge in Rhetoricam pseudolulliana", Revista Internazionale di Storia della Scienza, 16, 1974, pp. 223-233.

RAMíREZ VIDAL, Gerardo, El arte de la memoria en la Rhetorica christiana de fray Diego Valadés, México, 2012 (en prensa).

Urvoy, Dominique, "L'apport de Fr. B. de Sahagun a la solution du problème lullien de la compréhension d'autrui”, Estudios Lulianos, 18, 1974, pp. 5-24. 
